Viso: Cadernos de estética aplicada

Revista eletrônica de estética

ISSN 1981-4062

No 27, jul-dez/2020

http://www.revistaviso.com.br/
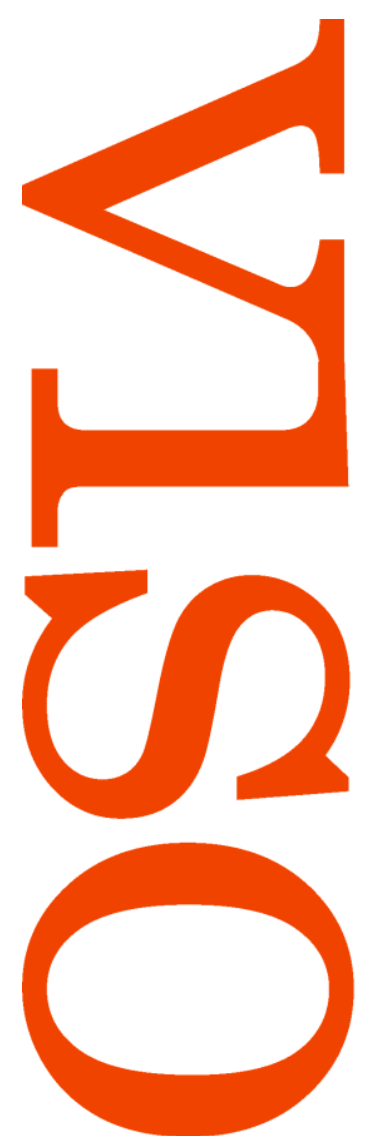

\title{
Querelas que interessam: Forensic Architecture e os paradoxos da arte e da política
} Luiz Camillo Osorio 


\section{RESUMO}

Querelas que interessam: Forensic Architecture e os paradoxos da arte e da política

A indecidibilidade entre arte e não-arte, inerente à cena artística desde Marcel Duchamp e característica fundamental do regime estético das artes, será tomada aqui como ponto de partida para pensar as intervenções do coletivo Forensic Architecture. Atuando entre tribunais internacionais de direitos humanos e museus de arte contemporânea, suas montagens lidam com vídeos, simulações 3D, diagramas, entrevistas, reconstruções arquitetônicas, sempre partindo de litígios reais cujos vereditos foram dados em situações de assimetria de poder. Independentemente de ser ou não-arte, o Forensic usa os espaços da arte e este "estado de arte sem arte" como fórum necessário para ampliar o debate sobre o que podemos ver, como recortamos o que cabe ser visto, qual nossa responsabilidade sobre o visível. Eles trazem para dentro do museu e do campo paradoxal da arte contemporânea um debate complexo sobre política, justiça e bem comum.

Palavras-chave

arte política; arte contemporânea; Forensic Architecture; Jacques Rancière; David Joselit

\section{ABSTRACT}

\section{Quarrels that Matter: Forensic Architecture and the Paradoxes of Art and Politics}

The indecidibility between art and non-art, intrinsic to the art world since Duchamp and main feature of the aesthetic regime of the arts, is used in the article to think about Forensic Architecture interventions. Acting between international courtrooms and art museums, their installations deal with videos, 3D simulations, diagrams, interviews, architectonic reconstructions, focusing in real conflicts and the assimtery of power. Beyond its artistic condition, assuming its "state of art without art", they appropriate art institutions as a forum to amplify the debate on what we can see, how we frame it and our responsability to the visible. They bring into the paradoxical field of contemporary art a complex debate on politics, justice and common good.

Keywords

political art; contemporary art; Forensic Architecture; Jacques Ranciere; David Joselit 
OSORIO, Luiz Camillo. "Querelas que interessam: Forensic Architecture e os paradoxos da arte e da política". Viso: Cadernos de estética aplicada, v. 14, $\mathrm{n}^{\circ}$ 27 (jul-dez/2020), p. 71-91.

DOI: $10.22409 / 1981-4062 / v 27 i / 379$

Aprovado: 24.10.2020. Publicado: 28.12.2020.

(c) 2020 Luiz Camillo Osorio. Esse documento é distribuído nos termos da licença Creative Commons Atribuição-NãoComercial 4.0 Internacional (CC-BY-NC), que permite, exceto para fins comerciais, copiar e redistribuir o material em qualquer formato ou meio, bem como remixá-lo, transformá-lo ou criar a partir dele, desde que seja dado o devido crédito e indicada a licença sob a qual ele foi originalmente publicado.

Licença: http://creativecommons.org/licenses/by-nc/4.0/deed.pt_BR

Accepted: 24.10.2020. Published: 28.12.2020.

(C) 2020 Luiz Camillo Osorio. This document is distributed under the terms of a Creative Commons Attribution-NonCommercial 4.0 International license (CC-BY-NC) which allows, except for commercial purposes, to copy and redistribute the material in any medium or format and to remix, transform, and build upon the material, provided the original work is properly cited and states its license.

License: $\underline{\text { http://creativecommons.org/licenses/by-nc/4.0/ }}$ 
"Fundamentalmente o que me interessa é a topografia do perceptível, do pensável e do possível". Jacques Rancière

"A história da arte é o embate entre todas as experiências ópticas, os espaços inventados e as figurações."

Carl Einstein

A motivação inicial deste texto é fazer uma homenagem à querida colega Noéli Ramme, que tão cedo nos deixou. 0 primeiro ato ocorreu na UERJ em uma mesa-redonda, ainda presencial, junto aos amigos Ricardo Barbosa e Jorge Sayão. Ali falei sobre Hélio Oiticica e seus atritos com o museu. Tratava-se de discutir, nos moldes das cenas montadas por Rancière, o conflito entre os parangolés e o MAM-Rio, desde a sua interdição em 1965, não sendo permitida a entrada dos passistas da mangueira e do artista no museu, até a inclusão na coleção das suas cópias expositivas em 1986, seguida, em 2002, da proibição de interação e uso pelo público. A canonização transformando a natureza performativa dos parangolés.

Sigo aqui tratando do problema da inadequação da arte, da fronteira movediça entre arte e não-arte, para, a partir daí, imaginar o quanto esta indecidibilidade do artístico pode abrir brechas para se construir outros modos de perceber as coisas e estar no mundo. Neste aspecto, tomo de maneira um tanto arbitrária o ponto de partida do meu diálogo com a Noéli, durante sua banca de tese de doutorado intitulada Arte $e$ construção de mundo, focada na filosofia de Nelson Goodman. Um dos elementos mais produtivos da leitura do filósofo norteamericano, para mim, foi o deslocamento da pergunta o que é arte, para uma outra, mais pragmática e perspectivada: quando é arte? Sem este deslocamento, creio que não podemos pensar efetivamente sobre arte contemporânea; mais do que isso, sobre seus efeitos no mundo, ou seja, sobre uma possível política da arte.

Trarei para o foco da análise o coletivo multidisciplinar Forensic Architecture, formado na Universidade Goldsmith de Londres e que atua entre tribunais internacionais, salas de museus e bienais. Eles produzem imagens e simulações que 
são ao mesmo tempo instrumento investigativo e experimentação "artística”. É esse deslizar, sempre atritivo, de um ambiente institucional para outro, de um território e prática discursiva para outra, que me interessa discutir. 0 atritivo, em parte, tem a ver com o fato de eles serem questionados nos tribunais por serem artistas e nos museus por não fazerem arte. Creio que sua presença no espaço expositivo é produtiva, acima de tudo, na medida em que põe em movimento a categoria arte política, tão desgastada desde o fim das vanguardas e sua inserção nos museus. Neste caso das montagens expositivas do Forensic, é justamente o não-lugar do museu, este espaço onde tudo parece possível, em que o tempo e o espaço cotidianos são postos em suspensão, que garante que suas evidências forenses ganhem mais publicidade e reverberação política.

Não se trata de querer dar à arte uma efetividade política imediata, mas de qualificar o modo pelo qual a política da arte implica sempre uma reconfiguração do sensível, que nos obriga a redefinir nossos modos de ver, falar e interpretar o real; ou seja, de ajuizá-lo sem regras a priori, engajando-nos neste processo de ajuizamento justamente por não sabermos como ver e identificar o que estamos vendo. Ajuizar não implica, pelo menos não necessariamente, normatizar, dizer como determinada situação deve ser, mas sim obrigar-se a percebê-la no que ela tem de singular. Discutir as "exposições" deste coletivo de ativistas não significa uma vontade de politização da arte, no sentido de sua instrumentalização, querendo que ela sirva às causas progressistas. Querer algo da arte é sempre um problema; aqui, é mais um não-querer que está em jogo, tanto nos tribunais como nos museus - não querer uma "justiça" que nega as evidências e não querer uma arte política que só fala para a sua própria bolha.

0 mundo da arte é bastante contraditório. As feiras e bienais movimentam milhões de dólares e de pessoas, fazendo circular obras e discursos das mais distintas regiões e culturas do planeta. Não obstante a diversidade, percebe-se também o que a historiadora Kaira Cabañas denominou, seguindo Derrida, de 
o Monolingusimo do Global. Para a autora, "o monolinguismo do global se manifesta, dentre outras formas, no pseudomorfismo desenfreado que caracteriza diversas exposições de arte contemporânea". ${ }^{1}$ Este pseudomorfismo caracterizar-se-ia pelo fato de muitas das exposições no universo globalizado da arte contemporânea aproximarem coisas díspares e disseminarem um mesmo repertório formal sem qualquer aderência histórica e cultural. Não se trata de negar a dimensão global da arte, mas apropriar-se dela de modo mais crítico e conflitivo. A questão é como produzir algum ruído no meio da fala hegemônica e consensual sobre o que seja arte.

Quero então sublinhar, trazendo o caso do Forensic Architecture, algo que me parece produzir algum ruído: a introdução da não-arte no espaço institucional da arte, não para fazer dela uma obra de arte, mas para deslocar as noções estabelecidas de arte quase sempre baseadas no discurso condescendente da sua auto-referencialidade. Este deslocamento não significaria abrir mão da autonomia da arte. Cabe diferenciar auto-referencialidade de autonomia. Quer-se, por um lado, recusar o ensimesmamento da arte, como se ela pudesse falar apenas de si mesma, buscando modos dissonantes de falar ao mesmo tempo de si e do mundo; por outro, quer-se manter a arte como um significante aberto que não se deixa determinar de fora, a partir dos discursos e sentidos já instituídos e estabelecidos. 0 regime estético da arte, segundo Rancière, "funda, a uma só vez, a autonomia da arte e a identidade de suas formas com as formas pelas quais a vida se forma a si mesma". ${ }^{2}$ Autonomia da arte é a defesa da indeterminação dos modos pelos quais ela se materializa e produz sentido. Indeterminação que se alia, portanto, ao processo de desidentificação frente aos sentidos instituídos. A arte segue podendo ser uma forma de distanciamento, enquanto suspensão de sentido, sem com isso alienar-se do mundo ou abrir mão de novas possibilidades de saber.

É conhecida a instabilidade ontológica da arte pelo menos desde o ready-made duchampiano. A fronteira a priori entre arte 
e um objeto qualquer desapareceu ali, pelo menos no sentido em que não há mais nenhuma qualidade plástica ou formal que garanta um modo específico de aparecer da arte. No momento ao qual me refiro, no presente, trata-se de radicalizar esta instabilidade, não mais para ampliar o que pode vir a ser arte, mas para manter ambíguo o estatuto artístico, abrindo, assim, a possibilidade da não-arte desestabilizar e vivificar nossos sentidos. Não se trata de mais uma ruptura nos modos de vermos a arte, mas de pôr em suspensão a percepção do mundo em que vivemos, desestabilizando as identificações estabelecidas, produzindo no espectador formas heterogêneas de sentir. O legado duchampiano foi ganhando novas reverberações, seja do ponto de vista das poéticas Pop que se apropriaram de todo um repertório de imagens cotidianas, seja da arte conceitual que misturou o discursivo e o visível, seja ainda do ponto de vista do espectador, convocando-o para uma apreensão menos acomodada do que se apresenta no campo da arte. Tudo isso tendo em vista uma inscrição mais política deste legado, que parecia confortável apenas com a desregulação do fazer artístico.

Neste sentido, como salientou Jacques Rancière, desde o momento de constituição do regime estético das artes, entre a terceira crítica kantiana e o Romantismo, a arte assumiu uma forma singular de eficácia política. Trata-se da

eficácia de uma desconexão, de uma ruptura
da relação entre as produções das
habilidades artísticas e dos fins sociais
definidos, entre formas sensíveis,
significações que podem nelas ser lidas e
efeitos que elas podem produzir. Pode-se
dizer de outro modo: a eficácia de um
dissenso. O que entendo por dissenso não é o
conflito de ideias ou sentimentos. É o conflito
de vários regimes de sensorialidade.

Com alguma inquietação e bastante interesse, temos visto serem incluídas em exposições de arte atividades ou práticas que não foram realizadas com esse propósito específico. Documentos de arquivo, cartazes publicitários, fotografia vernacular, reproduções sem valor de mercado, textos, tudo 
isso redimensionando circunstancialmente modos de aparecer e significar da arte. Pensemos, por exemplo, nos objetos relacionais de Lygia Clark: eles foram feitos tendo em vista uma intervenção terapêutica; entretanto, metamorfoseiam-se naquilo que a própria artista denominou de "estado de arte sem arte", ao entrarem em uma exposição. A partir desse momento ressignificam suas "obras" anteriores, dos Casulos aos Bichos, assim como reconectam arte e terapia, formas de participação estética e cuidado de si.

O mais importante não é o modo como nomeamos uma atividade ou objeto, tornar-se arte é uma virtualidade inerente ao modo pelo qual certa experiência, sob certas condições, mobiliza o espectador a produzir associações inesperadas na percepção que façam algum sentido na configuração deste vir a ser arte. O compartilhamento desta experiência e o desdobramento de sua condição de arte é fundamental, mas não cabe discutir aqui. Importante ressaltar que incluir um objeto qualquer em uma exposição não desqualifica, nem impede, obviamente, que sigamos considerando produções tradicionalmente consideradas como arte enquanto tais. Nem tampouco que esta outra atividade que eventualmente ganha status momentâneo de arte perca sua função original. Ela apenas acrescenta outra possibilidade, a de ser tomada como arte e com isso desdobrar uma articulação interpretativa e semântica que não estava prevista inicialmente. Por exemplo, diante da Fonte do Duchamp somos capazes de perceber a ironia do seu gesto poético; o mesmo objeto, em um banheiro, segue apenas com sua função utilitária.

Saindo do universo moderno da produção de objetos para o contemporâneo da circulação de imagens, resta-nos constatar quão assombrosas são as tecnologias que estão ao nosso dispor para disseminá-las na rede, fazê-las circular rapidamente e em escala global. Esta multidão de imagens em circulação carrega energias e potencialidades desconhecidas, que variam de acordo com as formas como venhamos a recortá-las e apresentá-las. As relações circunstancialmente produzidas com um determinado conjunto de imagens acabam por 
ressignificá-las, a cada contexto específico em que possam ser mostradas e recombinadas. Percebemos novas potências e intensidades veladas.

Passa-se de um mundo sensível a outro mundo sensível que define outras tolerâncias e intolerâncias, outras capacidades e incapacidades. 0 que está em funcionamento são dissociações: ruptura de uma relação entre sentido e sentido, entre um mundo visível, um modo de afeição, um regime de interpretação e um espaço de possibilidades; ruptura dos referenciais sensíveis que possibilitavam a cada um o seu lugar numa ordem das coisas. ${ }^{4}$

Para explicitar esta situação de desconexão da ordem das coisas, de multiplicação de formas de sentir e falar que redefinem formas de ver e atuar no mundo, vou analisar, como já dito, o coletivo Forensic Architecture. $O$ foco da atenção é menos para a qualidade em si das imagens, e sim o modo como eles constituem arranjos de imagens e simulações digitais, recompondo-as em busca de uma nova configuração de sentido tendo sempre uma situação litigiosa como ponto de partida. Diante destas imagens constata-se aquilo que a teórica Ariella Azoulay denomina responsabilidade do espectador diante das fotografias, uma vez que o "evento fotográfico nunca está terminado" ${ }^{\prime \prime}$, ficando sempre aberto a novas configurações de sentido para novos públicos e contextos.

Em sua página na internet, o coletivo londrino se apresenta de forma bastante objetiva:

Forensic architecture é uma agência de pesquisa independente baseada na Universidade Goldsmiths de Londres, que investiga violações de direitos humanos, violência cometida por corporações, estados, forças militares e policiais. As investigações empregam tecnologias de análise arquitetônica e espacial, assim como modelos digitais imersivos, entrevistas e uma equipe interdisciplinar de pesquisadores. As evidências são apresentadas em fóruns, tribunais, comissões da verdade e relatórios de direitos humanos, assim como nas 
principais instituições culturais, museus e assembleias comunitárias. ${ }^{6}$

Em 2018 foram finalistas do Turner Prize de arte contemporânea na Tate Britain. Levar o processo de uma investigação forense para uma exposição implica apostar que há algo no desenvolvimento deste trabalho de pesquisa que tangencia o campo da arte. Como salientou o crítico de arquitetura Rowan Moore, no jornal The Guardian, "em um mundo saturado de imagens, onde quase tudo ganha visibilidade, eles tentam trazer à tona o que estava velado. Eles denominam sua atividade de contraforense, sendo forense a arte da polícia". ${ }^{7}$ Todas as suas intervenções entram em situações polêmicas em que há assimetria entre poder instituído, indivíduos e movimentos sociais.

Nunca é demais ressaltar que este deslocamento institucional não quer dar ao conjunto de imagens e documentos levados ao espaço expositivo um verniz artístico, nem que o espectador passe a "contemplá-los" como se fossem arte. 0 que de fato acontece é que o espectador mobiliza um aparato perceptivo e interpretativo que não costuma mobilizar para imagens forenses. Ao mesmo tempo, saber tratar-se de casos concretos e litígios reais mobiliza um tipo especial de engajamento da parte do público. Toda esta situação é nova e interessante. A apresentação de um conjunto de imagens e simulações tecnológicas, tanto num tribunal como em um museu, implica lidarmos com os conflitos, preconceitos, silêncios e invisibilidades, articulando o que se mostra e o que se quer ver ou se pode ver, o que nos obriga a parar para olhar e, de algum modo, ajuizar.

O desafio está na possibilidade de fazer com que neste deslocamento desfaçamos a "pressuposição de um continuum sensível entre a produção de imagens, gestos ou palavras e a percepção de uma situação que empenhe pensamentos, sentimentos e ações dos espectadores". ${ }^{8}$ Quebrar o continuum aqui é quase que o efeito das perguntas que se nos impõem imediata e irrecusavelmente, a saber: como olhar estas evidências, o que pensar a partir delas, que tipo de juízo nos 
cabe fazer? Ou ainda: que partilha surge aí entre um litígio jurídico, uma montagem de imagens e textos, um olhar ajuizante e um posicionamento político? Será que levar estas investigações para uma exposição não retiraria delas a capacidade de intervenção na própria realidade? Por que misturar o desejo de revelar a verdade com o mundo da fabulação tão próprio à arte? Em que medida o espaço experimental da arte pode ser importante para potencializar as formas de visibilização dos fatos em uma época abalada pelas fake news?

Vejamos uma das intervenções do Forensic. Em janeiro de 2017, a polícia de Israel desocupou um assentamento Beduíno no deserto de Neguev. Um policial e um professor beduíno, tido como terrorista, morreram naquela noite. Pelo discurso oficial, o tal terrorista avançou com o seu carro sobre os policiais sendo abatido por eles. Pesquisaram em sites do Estado e pediram aos ativistas e moradores que enviassem todas as gravações feitas no local. Juntaram áudio e imagens, fizeram simulações, trabalharam com geolocalizadores e reconstruíram a cena no deserto, demonstrando, ao fim, que a versão oficial era absurda e que o professor foi assassinado e não era um terrorista. Evidentemente as forças policiais de Israel seguiram com a defesa da polícia, mas a opinião pública passou a ter acesso a uma outra versão, com evidências mais robustas sobre o que de fato se passou. ${ }^{9} \mathrm{Um}$ ponto importante é que o trabalho forense, normalmente usado pelas forças policiais, é aqui virado na direção oposta, desfazendo a versão policial e introduzindo uma dinâmica dissensual, logo política, através das recomposições apresentadas. 0 que acontece na maioria das intervenções do coletivo é buscar informações que desconstruam a versão oficial, não para contestar os fatos e as leis, mas para explicitar que ambos foram negligenciados. Em um mundo da pós-verdade, lutar por um tratamento mais adequado e rigoroso dos fatos é uma exigência crítica. 0 espaço da arte pode ainda ser mobilizado para nos fazer ver a realidade criticamente. 
Retomaria a partir daqui o modo como Jacques Rancière, em um livro recente, discute e problematiza os modos de vinculação entre ficção e realidade. Esta problematização do ficcional é o que me interessa mobilizar no interior deste debate sobre as fronteiras indefinidas da arte e da não-arte. Ou melhor, de modo a mostrar que é justamente nesta indecidibilidade do artístico que pode despertar no espectador e no leitor uma recepção desestabilizadora do que vemos e dizemos.

\begin{abstract}
A ficção não interessa pela invenção de seres imaginários. Ela é antes uma estrutura de racionalidade. É a construção de um quadro no seio do qual os temas, as coisas e as situações são percebidas pertencendo a um mundo comum, os acontecimentos são identificados e ligados uns aos outros em termos de coexistência, sucessão e causalidade. A ficção é requerida sempre que é produzido um sentido de realidade. Por isso, a ação política, as ciências sociais ou a prática jornalística usam a ficção tanto como os romancistas e os cineastas. ${ }^{10}$
\end{abstract}

0 trabalho com a linguagem pode levar a uma recombinação dos modos de ordenarmos e conectarmos fatos e sentidos. Se isto em um texto literário é imperativo, em um artigo de jornal ou um documentário é uma potencialidade que obriga a imaginação a se desprender do mero reconhecimento do que vê, desestabilizando sua função instrumental ligada à representação e, assim, mobilizando um ajuizamento sem norma - imaginação produtiva levando à instauração de sentido (ou de jurisprudência). Esta potência instauradora, ressaltada pela indefinição entre arte e não arte, gera uma ambivalência produtiva, remetendo a uma função criativa no juízo do espectador, que, sem saber como identificar o que vê, se põe a imaginar, a experimentar possibilidades de ver.

Trata-se de uma aposta de que este material do Forensic Architecture, ao ser deslocado para o espaço da arte, consiga produzir outras formas de atenção e escuta, menos pressionadas pela urgência da decisão. Neste ambiente, ficamos mais disponíveis a olhar as coisas por conta própria e, 
assim, responsabilizarmo-nos pelo que vemos. A emancipação do espectador nada mais é do que a possibilidade de qualquer um assumir a autoria sobre o sentido daquilo que vê. Como apontou David Joselit em seu último livro, "o sentido das imagens não deve ser tomado como algo dado e nem fixado na sua forma ou conteúdo - o trabalho estético implica a determinação das condições sociais e geopolíticas que autorizam o aparecer destas imagens". ${ }^{11}$

Um dado a ser acrescentado aqui é que o coletivo londrino é seguidamente desacreditado e desautorizado nos tribunais pelas autoridades forenses oficiais. Como dizem seus integrantes, a operação que realizam é mais que tudo contraforense. Isso faz com que a entrada no território inespecífico da arte sirva para de algum modo reverberar publicamente o debate. Este foi o caso quando de sua participação na Documenta de Kassel de 2017, que reacendeu a discussão sobre o assassinato, em 2006, de um imigrante turco, que gerenciava uma lanhouse na própria cidade de Kassel. Crime cometido por um neonazista, com alguma cumplicidade de um agente da inteligência do estado de Hessen. 0 principal objetivo era levar a investigação ao parlamento na tentativa de criminalizar as ações terroristas do grupo neonazista NSU (National Socialist Underground). ${ }^{12}$

Entretanto, apesar de reacender o debate, segundo uma das participantes do coletivo, "a investigação foi desqualificada pelo Partido Democrata Cristão por ser um trabalho não rigoroso conduzido por um grupo de artistas - não obstante a presença de especialistas em balística, dinâmica dos fluidos e acústica". ${ }^{13}$ Se havia dúvida se as montagens do Forensic eram ou não arte, o Parlamento Alemão deu seu veredito - é arte, e por isso deve ser desacreditado como evidência forense. Cabe retomar a noção de cidadania da informação apontada por Joselit. Segundo ele, vivemos em um mundo cujas instituições políticas e jurídicas, limitadas a contextos nacionais e a fronteiras restritivas, são pouco disponíveis para lidar com os problemas e conflitos globais. Neste aspecto há um potencial para as instituições culturais funcionarem "como uma esfera 
pública transnacional adiantando-se às instituições geopolíticas convencionais, ainda congeladas em um quadro de referência pouco desenvolvido". ${ }^{14}$

A noção de arte vem se transformando de forma radical há décadas. A virada conceitual dos anos 1960 multiplicou os processos poéticos e a própria materialidade da arte. Documentos, registros e fotografias foram sendo incorporados e passaram a existir novas articulações entre narrativas conceituais e experiência estética. Em vez da saída do museu, há uma crítica institucional e uma institucionalidade crítica, introduzindo práticas híbridas e novos formatos artísticos. Não se deve, contudo, abandonar a noção de experiência estética, mas tomá-la em novas bases, uma vez que seguimos potencializando novas formas de ver, expressar e partilhar 0 que entendemos como realidade e como arte. Como demonstrou Thierry De Duve, a questão estética migrou, desde Duchamp, da questão clássica, isso é belo, para uma mais desnorteadora, mais que nunca radicalizada, sobre ser ou não arte. Diante da pergunta isso é arte, desdobram-se outras: que implicações tem esta possibilidade de arte para a minha vida e para o mundo à minha volta?

O livro anterior de David Joselit, After Art, pode nos ser bastante útil para pensarmos sobre estas transformações do modo de ser da arte depois da virada conceitual e, consequentemente, das montagens expositivas que exploram material nãoartístico. Para começo de conversa, como traduzir este after? Preferiria a partir da arte em vez de depois da arte. Assim, a condição artística fica ressaltada mesmo que se vá além dela, não se fixando na mera condição de obra de arte. Muito do que foi sendo percebido como arte, desde o começo do modernismo, pelo menos, foi se dando apesar de a categoria "arte" não ser, em alguns casos, suficiente para definir o que estava sendo visto. Tomemos, por exemplo, um desenho do Rafael $^{15}$, realizado nos ateliês do hospital psiquiátrico do Engenho de Dentro: é uma obra de arte e também algo a ser usado na análise da esquizofrenia e para a humanização do seu tratamento. É arte e mais do que arte, ou seja, junto e a 
partir da arte outras funções se destacam, se somam à função artística, sem uma eliminar a outra.

De maneira análoga, uma investigação forense, mesmo não tendo sido inicialmente, é óbvio, produzida com o intuito de ser arte, pode mobilizar nossa percepção como se fosse arte, deslocando o que se sabia e o que se imaginava possível de ver. Não estou dizendo que sejam a mesma coisa - Rafael e Forensic - mas sim que ambos exigem do espectador que experimente formas de recepção não normativas, que façam aquilo que toda obra de arte exige - assumam para si o trabalho de interpretação/criação de sentido. Usando para isso um repertório crítico que misture as referências que trazemos de nossas experiências anteriores junto com nossa capacidade de produzir sentidos no interior de uma disputa por interpretações contraditórias. A arte como suspensão de sentido que nos faz reconfigurar o comum, instaurando um modo de ver o real mais complexo e abrangente. Curiosamente, não se trata mais de desconfiar dos fatos, mas de dar-lhes uma interpretação mais consistente.

Para Joselit, um dos objetivos de seu livro After Art seria o de expandir a definição de arte "incorporando configurações relacionais heterogêneas, que o artista francês Pierre Huyhgue denominou de uma cadeia dinâmica que se apropria de diferentes formatos". ${ }^{16}$ O fato, ressaltado acima, de uma investigação do Forensic Architecture passar de um tribunal para um espaço expositivo, não deve ser visto como uma contradição entre fato e ficção, mas como potencialidades inerentes à maneira como a imagem é tratada e disseminada, tendo em vista a possibilidade de funcionar seja como evidência forense seja como revelação poética - tendo sempre como intuito a capacidade de dar a ver algo que até então não era visto.

Um ponto importante em toda a discussão de Joselit é o uso dado à noção de formato - em vez de obra ou meio expressivos. Os formatos explorados em cada exposição do Forensic implicam uma disposição nova, capaz de intensificar 
os modos de olhar, sem o imediatismo do tribunal e atravessado pela necessidade de ajuizar e tomar posição. Não há um deslocamento de uma dimensão objetiva das evidências jurídicas para uma dimensão subjetiva do olhar estético; o que há é uma aposta na possibilidade de intervir nos litígios contemporâneos nos convidando a participar das partilhas do sensível que "ensejam novos modos de sentir e induzem novas formas da subjetividade política", sabendo-se que a política "ocupa-se do que se vê e do que se pode dizer sobre o que é visto, de quem tem competência para ver e qualidade para dizer, das propriedades do espaço e dos possíveis do tempo". ${ }^{17}$

É através das montagens que o gesto poético e o gesto político complementam-se. Neste aspecto, voltando a Joselit, os formatos, por serem "estruturas provisórias e heterogêneas que mobilizam diferentes conteúdos"18, produzem modos de circulação variados que garantem endereçamentos também variados. Os formatos são uma categoria interessante na medida em que assumem a indecidibilidade e a contingência do artístico, remetem a uma estética das conexões, não de objetos, apostando em uma noção mais dinâmica da temporalidade da forma. Esta vai emergindo ao longo da experiência de cada um, sem se deixar fixar, como um processo que vai se dando a partir da disposição/composição/articulação de imagens, textos e diagramas. Isso pressupõe uma revisão de nossos critérios de apreensão e de crítica, uma vez que a percepção e a interpretação, o ver, o falar e, eventualmente, o escrever, vão se complementando sem que haja uma relação causal entre eles. Assume-se assim algo que já estava claro na tarefa da crítica desde o romantismo e mais enfaticamente desde Benjamin que ela é um desdobramento do gesto criativo sem com isso fazer da crítica uma forma de arte. Não seria difícil desdobrar daí o movimento sublinhado por Rancière de aproximar a ação necessária do espectador daquela do tradutor. Exigindo na experiência da arte o equacionamento entre passividade e atividade, pathos e logos, sentir e pensar, obrigando os espectadores a desempenharem "o papel de intérpretes ativos, que elaborem sua própria tradução para apropriar-se da 
"história" e fazer dela sua própria história. Uma comunidade emancipada é uma comunidade de narradores e tradutores". ${ }^{19}$

Esta emergência de um formato que traduza as evidências em imagens, as imagens em textos e a combinação deles numa "arte sem arte", vai se dando a partir das relações que vamos produzindo a partir de nossas disponibilidades estéticas, conceituais, políticas, que interferem, por sua vez, no processo de experienciá-las. Formatos são configurações de força e não mais objetos específicos. Traçar estas forças, desvendá-las e produzi-las, é algo que se dá a partir do modo como somos afetados e do que fazemos a partir daí. Caberia ao crítico (e ao espectador) analisar conexões, compor modos de sentir com formas de dizer, redefinindo nossas interações com uma realidade fugidia e dissonante. A arte segue sendo este acontecimento indeterminado que nos abre novas possibilidades não só de percepção de novas formas de expressão e de experimentação com a linguagem, mas também de transformação dos modos de se conectar com o mundo, com a realidade a nossa volta, sempre plural, aberta e em disputa.

Diferentes perspectivas e campos do saber devem ser compostos e reconectados. Desde Joseph Beuys e seu Fórum para a Democracia Direta, criado na Documenta de 1972, a defesa de que todos são artistas é uma forma de expandir o alcance do exercício de liberdade inerente ao fazer experimental da arte. Este exercício deve ser multiplicado dado o esgotamento dos princípios iluministas que compunham uma ideia de sujeito, de racionalidade e de sociabilidade. Desdobrase daí a crise da política enquanto lugar de trocas sobre um mundo em comum. Resta, na melhor das hipóteses, aos espaços da arte, mesmo com suas contradições intrínsecas, inventar novos repertórios expressivos que reintroduzam um mínimo de articulação entre afecções, palavras e coisas. Sem isso, não haverá mais compartilhamento de mundo e nem a liberdade de pensarmos diferente. 
Expor na Tate ou na Documenta de Kassel não deveria comprometer o caráter investigativo dos casos trabalhados pelo Forensic Architecture. Em um mundo ainda muito separado por especialidades e disciplinas, essa circulação entre a universidade, os tribunais e os museus deveria ser alvissareira, jamais comprometedora. Mas o poder teme a indisciplina, cabendo à arte dar-lhe alguma guarida. Sem desqualificar as especificidades de cada um destes campos do conhecimento, a possibilidade de cruzar fronteiras, misturar discursos e viabilizar novas composições enunciativas é o caminho possível para enfrentar o descolamento perigoso entre fatos e narrativas. 0 que acontece no espaço expositivo é um pôr em cena de imagens que são ao mesmo tempo evidência e deslocamento, que nos mostram o que pode ter havido, nos fazendo ver o que não havia sido visto. Neste aspecto, "a cena é o operador que permite compreender o mundo a partir do conflito quanto às fronteiras que separam o que está dentro do que está fora, aquilo que existe daquilo que não existe, o que faz sentido e o sem sentido" ${ }^{20}$

Ser arte ou não ser arte não me parece uma questão, a questão é o que fazemos com aquilo que chamamos de arte por não termos um nome melhor e como isto interfere nas nossas formas de sentir, pensar e agir no mundo. Quando algo passa a ser visto como arte ou entra no espaço da arte sem ser arte, mobilizamos um tipo de atenção que está aberta a imaginar outras formas de mundo. Somos atravessados pela virtualidade do que não está dado, liberados do que já foi visto e convidados a ver e falar sobre o que não sabemos, mas que queremos saber a partir deste encontro. Sem isso não há nada que nos faça acreditar em um mundo em comum. A arte se manifesta na cisão entre ver e reconhecer, abrindo uma brecha que nos permite imaginar uma possível construção de mundo. Quiçá o Nelson Goodman e a Noeli Ramme falassem disso. 0 Forensic Architecture também. 


\section{Referências bibliográficas}

AZOULAY, Ariella. Civil Imagination. Londres: Verso, 2012.

CABAÑAS, Kaira. "O monolinguismo do global”. O que nos faz pensar, v. 26, n. 40 (junho 2017), p. 119-134. Disponível em: $<$ http://oquenosfazpensar.fil.puc-

rio.br/index.php/oqnfp/article/view/552>. Acesso em 17/11/2020.

JOSELIT, David. After art. New Jersey: Princeton University Press, 2013.

Heritage and Debt. Massachussets: MIT Press, 2020.

MOORE, Rowan. "Forensic Architecture: Detail Behind the Devilry". The Guardian, 25/02/2018. Disponível em: <http://www.theguardian.com/artanddesign/2018/feb/25/fore nsic-architects-eyal-weizman>. Acesso em 17/11/2020.

RANCIÈRE, Jacques. A partilha do sensível. São Paulo: Editora 34, 2005.

—. O espectador emancipado. Tradução de Ivone C. Benedetti. São Paulo: Martins Fontes, 2014.

. Les temps modernes: art, temps, politique. Paris: La fabrique éditions, 2018.

"La pensée des bords". Entretien réalisé par Fabienne Brugère Éditions de Minuit. Critique, n. 881 (Octobre, 2020).

WEIZMAN, Eyal (Director Forensic Architecture). Forensic Architecture: Violence at the Thereshold of Detectability. New York: Zone Books, 2017.

Luiz Camillo Osorio é professor do Departamento de Filosofia da PUC-Rio.

${ }^{1}$ CABAÑAS, 2017, p. 121.

${ }^{2}$ RANCIÈRE, 2005, p. 34

${ }^{3}$ RANCIÈRE, 2014, p. 59

${ }^{4}$ RANCIÈRE, 2014, p. 67. 
${ }^{5}$ AZOULAY, 2012, p. 25 ("The event of photography is never over").

6 Informações retiradas do site do coletivo (https://www.forensicarchitecture.org/): "Forensic Architecture (FA) is a research agency, based at Goldsmiths, Unuiversity of London, investigating human rights violations including violence committed by states, police forces, militaries, and corporations [...] Our investigations employ pioneering techniques in spatial and architectural analysis, open source investigation, digital modelling, and immersive technologies, as well as documentary research, situated interviews, and academic collaboration. Findings from our investigations have been presented in national and international courtrooms, parliamentary inquiries, and exhibitions at some of the world's leading cultural institutions and in international media, as well as in citizen's tribunals and community assemblies".

7 MOORE, 2018, p. 1 ("In a world saturated by images, where seemingly almost everything is exposed to view, they try to make visible those things that are kept hidden. They prefer to call their activity 'counter-forensics', 'forensics' being 'the art of the police'").

${ }^{8}$ RANCIÈRE, 2014, p. 54

${ }^{9}$ Para quem quiser conhecer melhor este projeto é possível ver o filme no site do coletivo: https://forensic-architecture.org/investigation/killing-inumm-al-hiran.

${ }^{10}$ RANCIÈRE, 2018, p. 14 ("La fiction n'est pas l'invention d'êtres imaginaires. Elle est d'abord une structure de rationalité. Elle est la construction d'um cadre au sein duquel des sujets, des choses, des situations sont perçus comme appertenant à um monde commun, des événements sont identifiés et liés les uns aux autres em termes de coexistence, de succession et de lien causal. La fiction est requise partout où il faut produire um certain sens de réalité. C'est pouquoi l'action politique, la science sociale ou la pratique journalistique usent de fictions, tout comme les romanciers ou les cinéastes").

11 JOSELIT, 2020, p. 251 ("The meaning of images must not be taken as given or inherently encoded in either their form or content - aesthetic work lies in determining the social and geopolitical conditions under which an image is authorized to appear").

${ }^{12}$ Para acompanhar este caso é possível acessar em: https://forensicarchitecture.org/investigation/the-murder-of-halit-yozgat.

13 Esta passagem pode ser vista online:

https://www.dezeen.com/2018/04/27/turner-prize-shifted-focus-onto-

issues-forensic-architecture/ ("According to Varvia the report was dismissed by the Christian Democrat Party as work from an unserious "artist group", even though it had expert testimony from ballistic, fluid dynamics and acoustic experts").

14 JOSELIT, 2020, p. 229 ("The potential for visual culture to function as a transnational public sphere in advance of conventional geopolitical institutions characterized by the kinds of underdeveloped frameworks for global justice"). 
${ }^{15}$ Não o artista renascentista, mas o artista-interno do hospital psiquiátrico do Engenho de Dentro, que participou dos ateliês de psicoterapia criados pelo artista Almir Mavigner e pela Dra Nise da Silveira em 1946.

16 JOSELIT, 2013, p. 48 ("To embrace heterogeneous configurations of relationships or links, what the French artist Pierre Huygue has called a dynamic chain that passes through different formats").

${ }^{17}$ RANCIÈRE. 2005, p. 17.

18 JOSELIT, 2013, p. 52 ("is a heterogeneous and often provisional structure that channels content").

${ }^{19}$ RANCIÈRE, 2014, p. 25.

${ }^{20}$ RANCIÈRE, 2020, p. 840 ("la scène est l'opérateur qui permet de comprendre un monde à partir du conflit sur ce bord qui sépare ce qui est dedans et ce qui est dehors, ce qui 'existe' de ce qui 'n'existe pas', ce qui fait sens de ce qui ne le fait pas"). 